\title{
Think Process, Think in Time: Advancing Study of Informing Systems
}

\author{
Bob Travica \\ University of Manitoba, Winnipeg, Manitoba, Canada
}

btravica@ms.umanitoba.ca

\begin{abstract}
The purpose of this article is to contribute to theorizing the process dimension of informing systems. The conceptualization draws on a framework called the Informing View of Organization and, particularly, on its segment of informing process. The article discusses the concept of informing process and its background in the process view of organization and explores the relationship between informing process and informing system on several examples. The main conclusion is that an informing system facilitates an initial positioning of a research (or practical) problem in systems terms, while the infoprocess stance enables dynamic and analytical view of connected activities that lead to business completion, modern technologies, and performance measurement. Parallels with complex systems theory are also demonstrated. Directions for further research are outlined.
\end{abstract}

Keywords: Informing Science, informing systems, Informing View of Organization, informing process

\section{Introduction}

In the past fifteen years, informing science has been developing as a trans-discipline that builds on various research traditions focused on problems of informing in different contexts (see Gill \& Cohen, 2009). A model of informing system has been one of the corner stones in informing science (Cohen, 1999/2009; Gill \& Bhattacherjee, 2009). It is based on Shannon and Weaver's (1949) technical model of communication created for engineering the transfer of telephone signals. Following this referent model, an informing system involves a sender and a receiver connected by a channel. Informing science scholars have made certain adjustments to the referent model, in order to make it more suitable for human communication and the social context. Terminologically, a sender provides information to a client via a delivery system (technologymediated or not), both parties residing in their respective social contexts. The breadth of informing system model has made it suitable for research in various social contexts and at different levels of analysis. However, it can be argued that the depth of the informing system model is unnec-

Material published as part of this publication, either on-line or in print, is copyrighted by the Informing Science Institute. Permission to make digital or paper copy of part or all of these works for personal or classroom use is granted without fee provided that the copies are not made or distributed for profit or commercial advantage AND that copies 1) bear this notice in full and 2) give the full citation on the first page. It is permissible to abstract these works so long as credit is given. To copy in all other cases or to republish or to post on a server or to redistribute to lists requires specific permission and payment of a fee. Contact Publisher@InformingScience.org to request redistribution permission. essarily limited, and particularly so with regard to process aspects.

Similarly to informing science albeit on a smaller scale, the framework Informing View of Organization (IVO) has also been developing on interdisciplinary grounds (Travica, 2005a, in press). IVO has been inspired by and it contributed to informing science (e.g., Travica 2005b, 2007). Conceptual simi- 
larities and differences between the two were drawn while IVO was still under development (Travica, 2006). Now that IVO is completed it is sensible to revisit its relationship with informing science. In particular, how does IVO relate to the model of an informing system? More specifically, IVO is focused on the concept of information system (IS) and treats it as part of a larger process of informing. Since IS is the delivery system in an informing system, the question becomes: what is the relationship between IVO's concept of informing process and informing science's concept of informing system? This question motivated the conceptual study reported in the present article. Given the fundamental role that the model of an informing system has in informing science, exploring its relationship with informing process can reveal more completely relationships between IVO and informing science.

The discussion that follows will first introduce the concept of informing process as a segment in the IVO framework. Next, the model of an informing system will be discussed and compared with the informing process approach on several examples. The discussion will conclude by demonstrating a normative use of the informing process approach for study of mobile enterprise.

\section{Infoprocess and IVO Framework}

Before introducing the concept of infoprocess, several points on the larger IVO framework will be made. The IVO framework brings together information system research, organization and management theory, cognitive psychology, communication theory, and semiotics. The primary interest of IVO is with the phenomena of informing in organization. The start premise is that information systems and informing in general are to be placed in organization as their natural context. Such a premise had been advanced in several streams of interdisciplinary research, such as information ecology, social informatics, and informing science. IVO has taken organization theory (a synthetic discipline in itself) as its main perspective on organization, and in particular so called organizational views that chart a historical trajectory of organization theory (structural, cultural, political, etc.). Progressing through interplay between conceptualization and empirical investigation, which have fueled each other, IVO has matured into a complete framework for research, theory making, and management.

IVO turns the classical view of organization around a concept of informing agents. This term refers to knowledge, data, meaning (synonymous with information), wisdom, and information technologies in their systemic deployments. All these are commonly referred to as informing agentscognitive and technological. IVO introduces seven aspects (segments) that result from intersecting informing agents with traditional views of organization (individual, group, structural, cultural, political, economic, and process). As shown in Figure 1, the staple IVO aspects are homoinformaticus, groupomatics, and five aspects that deploy the term "informing" in its truncated forminfostructure, infoculture, infopolitics, infoeconomics, and infoprocesses. Some of these aspects have a deeper traction in the literature including similar labeling (e.g., infoculture and politics of information), while others are new conceptualizations, equally well-rooted in the literature. Metaphorically, the framework has been likened to an eye that enables a new perspective on organization at various levels (Travica, 2005a). Informing agents shape the center of the IVO eye, where yin-yang design insinuates interrelatedness of cognition and technology. (Communication technology is implied as a variant of information technology).

The main purpose of IVO is to serve as a guide for research and management of information systems. This is represented by the middle orbit in Figure 1, which maps the entire life cycle of information system. As information systems are involved in all organizational aspects (individual, process, structure, culture, etc.), IVO offers a methodology for strategic alignment between organization and information systems. 


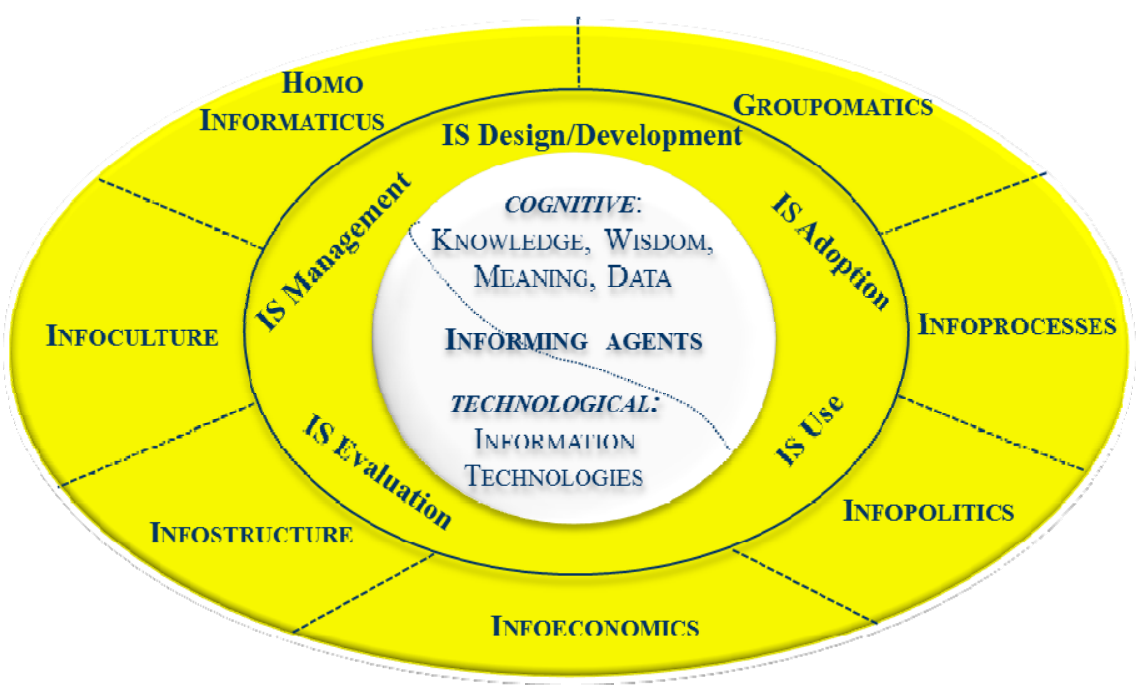

Figure 1. Informing View of Organization

Cursory descriptions of IVO aspects appear in Table 1. Due to limitations inherent to the form of journal article, further elaboration cannot be supplied here but can be sought in other publications (Travica, 2005, in press).

Table 1. Aspects of Informing View of Organization

\begin{tabular}{|c|c|}
\hline IVO Dimension & Concept \\
\hline Homo Informaticus & $\begin{array}{l}\text { Individual cognitive aspects and informing behaviors; individuals as } \\
\text { users and creators of organizational information technologies and sys- } \\
\text { tems. }\end{array}$ \\
\hline Groupomatics & $\begin{array}{l}\text { Group cognition, decision making, work and group support informa- } \\
\text { tion systems. }\end{array}$ \\
\hline Infostructure & $\begin{array}{l}\text { Stable relationships between data segments and the arrangements of } \\
\text { information technologies that complement social structure. }\end{array}$ \\
\hline Infoprocesses & $\begin{array}{l}\text { Processes of data manipulation and of cognition, external and internal } \\
\text { to homo informaticus. }\end{array}$ \\
\hline Infoculture & Stable beliefs, behaviors, and artifacts related to informing agents. \\
\hline Infopolitics & Agendas, power, and fight/flight behaviors related to informing agents. \\
\hline Infoeconomics & $\begin{array}{l}\text { Costs, benefits, and other organizational performance aspects related } \\
\text { to informing agents. }\end{array}$ \\
\hline
\end{tabular}

The infoprocess segment in IVO has been inspired by the process approach in management theory. In contrast, organization theorists have been reluctant to acknowledge a distinct process view of organization and opted for the cognate systems approach instead (cf. Hatch, 1997; Scott, 1992). This is curious given a long history of thinking of organization in process terms, which extends to date. A century ago, Frederick Taylor was occupied with designing work steps in sequences that would maximize task efficiency. Barnard (1938) conceived "executive process" in terms of managing by sensing an organization as a whole. In the 1950s, William E. Demming applied statistics and process analysis to controlling quality of manufacturing processes. His work 
gave rise to Total Quality Management and Kaizen methodologies, both revolving around process thinking and aiming at improvement of organizational/business processes.

Business Process Reengineering (BPR) was a more recent rendering of the process approach, which addressed the role of information technologies as a new dimension (Davenport, 1993; Hammer, 1996; Hammer \& Champy, 1993). Subsequently, the list of American contributors was expanded internationally by proponents of Business Process Management (BPM) that developed partly in reaction to radicalness of BPR (see vom Brocke \& Rosemann, 2010). BPM professes a systematic attention to organizing around process models (Hammer, 2010; Wong, 2013). It is assumed that any sort of work can be improved by treating it as a process (Davenport, 2010).

In general systems theorizing, process and system are two faces of the same phenomenon. Both represent a whole made of interrelated parts that work together toward achieving a common goal. On the difference side, "system" invokes a more static view focused on diverse parts and their interrelationships, while "process" engages a more dynamic stance revealing how some transformation unfolds through a succession of steps (phases, stages). Philosophically, differences between system and process resemble the dichotomy of structure vs. action.

In BPR and BPM, business process refers to a set of steps (workflow or interlinked procedures) connected from a start to an end point that deliver a value for the process customer (outside or inside an organization). Some steps are physical, some data-related, and others are mixed. The customer value proposition is the key for determining design of business process, such as its scope that may extend beyond departmental and organizational boundaries. The customer focus also features in measurement of business process performance (Harmon, 2007).

An organization can be viewed as a whole consisted of business/organizational processes (henceforth, processes) as shown in Figure 2. This is consistent with systems thinking in organization theory that an organization as a whole is a transformation process of environmental inputs into goods and services. But the process view of organization drills deeper into organization. It decomposes organization to a set of processes and sub-processes down to a level where further decomposition is not possible.

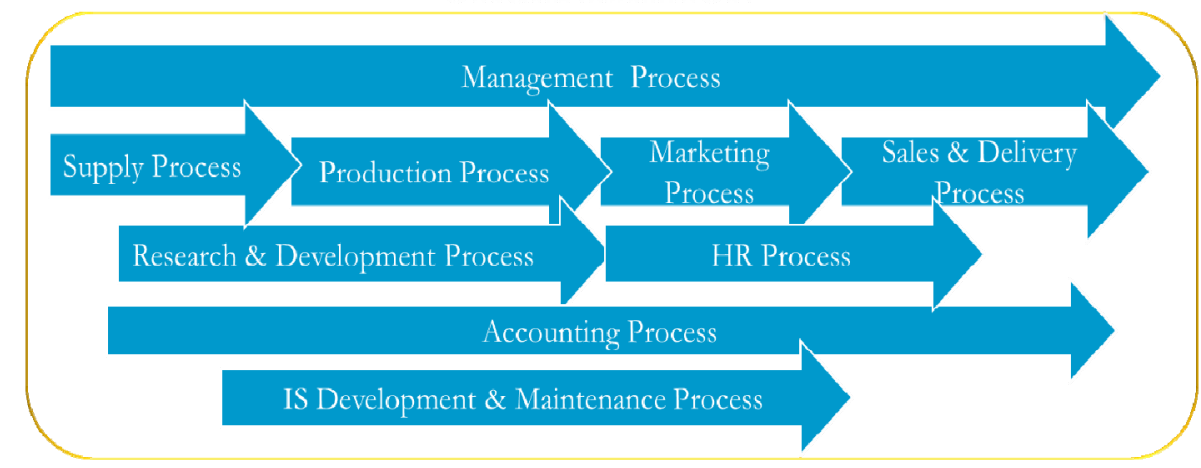

Figure 2. Process View of Organization

(Travica, in press)

The merit of the process view is that the actual work of transforming matter and data can be clearly defined and managed. The structural view of organization, which looks at jobs, tasks, and departments, lacks this capability. A process exhibits design that is most apparent as a composition of process steps and their sequencing. Less visible design aspects include coordination between process steps (e.g., sequential and parallel), complexity (e.g., the extent of decision points and loops), flexibility (variation in process execution), hierarchy (relationships between a process 
and sub-processed), and technology (information technologies and others). Process design can be optimized to yield a better process performance.

Process performance is measured usually in customer value, timing, and monetary cost. Of course, these are not mutually exclusive dimensions; for example, customer value can overlap with timing efficiency. Hammer (1996) underlined the design-performance relationship by positing that a process creates customer value only if process components function as a whole and contribute equally to the end result (design aspects of composition and coordination). Here is where additional merit of the process view is: one may detect design slack (unnecessary steps, delays, communication errors, misfits between individual tasks and the whole and even entirely odd processes) that diminishes customer value or time/money efficiencies.

\section{Properties of Infoprocess}

The IVO concept of infoprocess (short for "informing process") is based on the concept of business process discussed above. Infoprocess refers to interrelated informing activities that deliver an outcome to a customer. In other words, infoprocess accounts for immaterial or cognitive components of a business process. Infoprocess is composed of the data, cognition, and fundamental layer (Figure 3). Data processes carry business operations and involve activities of data collecting, entering, storing, retrieving, transferring, transforming, and displaying (to name few). These are carried by information systems and/or people and are studied usually in the fields of management information systems, library and information science, and so on. Cognitive processes involve perceiving, memorizing, retrieving memory, thinking, feeling, and learning. These phenomena are in the focus of cognitive psychology. In IVO, cognitive processes frame the conceptualization of homo informaticus, an introduction to which appeared in Travica (2007).

The middle layer in the infoprocess image represents the fundamental informing process by which data are transformed into meaning in the human mind. In IVO, "meaning" and "information" are synonyms. The fundamental informing process interfaces data processes and cognitive processes. It runs each time when a person engaged in a business process perceives external cognitive stimuli, be it in the form of oral communication, document, or output from an information system. This aspect of infoprocess is called "fundamental" in order to underline the ultimate purpose of infoprocesses. This is congruent with the purpose of informing system in informing science.

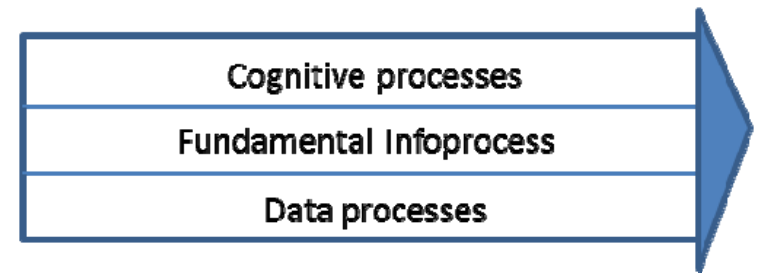

Figure 3. Infoprocess Composition

The IVO concept of information is rather unorthodox in some academic fields, such as management information systems. The step of cognitive involvement of the user of information system is typically bypassed. It is assumed that a system output is certainly to be understood by the user if it is "meaningful." It is the role of technology to bring the data it processes into a meaningful state, and therefore the system output can readily be qualified as "information." However, formal definitions or metric of meaningfulness and meaning are missing, being left to scholars' arbitrary approximations. A theoretical counter-argument to these propositions, which was formulated as INIS Principle, can be found elsewhere (Travica, 2011, 2012). For an instant empirical test it suffices to assume that a system output (or oral communication for that matter) is in a foreign language that the user/client does not know. Would it then qualify as information? Certainly not. 
Apparently, knowledge or engagement of cognitive processes is necessary for the client to be informed. Knowledge spans from elementary levels (e.g., knowing letters, how to read, common sense concepts) to higher levels (e.g., knowing specialist vocabularies, cause-effect relationships, analytical and problem solving methods, to knowing how to create new knowledge based on the information learned).

Information (meaning) is a result of the informing process. Someone who gets informed is the one that "gets information." Others do not, even though they perceive the same content. Therefore, IVO locates information in human cognition. The outside is the domain of data, no matter how much processed and organized they are. Labeling data content by its genre is preferable to sheer replacement of "information" with "data" (Travica, 2011). These propositions have anchoring in semiotics and communication theory that reaches beyond the conduit sender-receiver model, for example the theory of coordinated management of meaning by Cronen and Pearce (1982). The trans-disciplinary character of informing science makes it more susceptible to these ideas. For instance, Bednar and Welch (2009) invoked very similar ideas of Swedish computer scientist Langefors; Knox (2009) pointed out to the literature that conceptualized information as process; and Cohen (1999/2009) endorsed Boland's (1987) premise that "information is the inward-forming of a person that results from an engagement with data."

Another property of infoprocess important for this discussion refers to its relationships with other IVO aspects (Figure 4). A new infoprocess is shaped by the organization of existing data (infostructure), use patterns of information systems (infoculture), and so on, and may also exert influence on these when decisive support of organizational members and information systems is behind it.

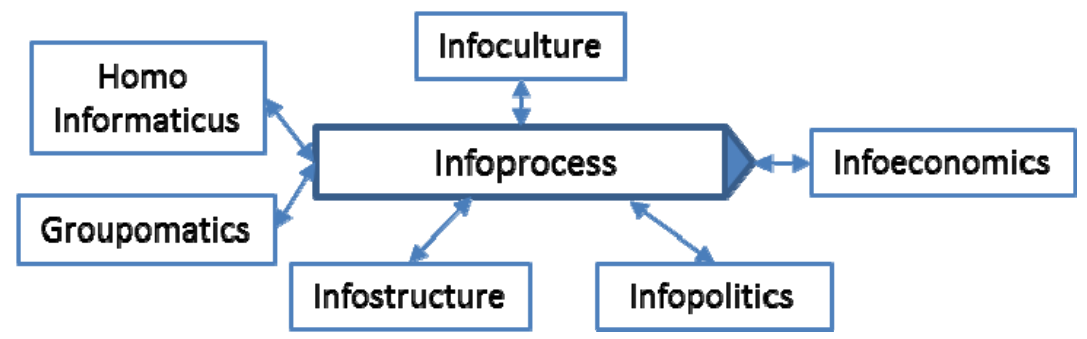

Figure 4. Infoprocess and Other IVO Aspects

Once established, infoprocess shapes the organization of new data, power relationships based on data and knowledge control (infopolitics), and economic effects (infoeconomics).

\section{Informing System: Potentials and Limitations}

The model of informing system has been a cornerstone of informing science (Cohen, 1999/2009; Gill \& Bhattacherjee, 2009). It is essentially based on the model that Shannon and Weaver (1949) developed for the purposes of explaining and engineering transferring of telephone signals. Therefore, the sender and receiver are connected via some medium (channel) that transfers a message from the former to the latter (see Figure 5). This modeling continues the tradition of deploying the Shannon and Weaver model in social sciences along with the commonly accepted conceptual transformation of sender and receiver devices to human actors and electrical signal to "information." 


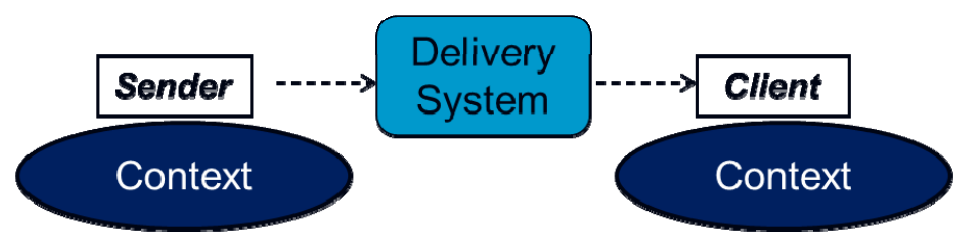

Figure 5. The model of Informing System

Informing science scholars have made certain adjustments to the referent model. As depicted in Figure 5, the receiver is renamed to "client," in agreement with the assumed purpose of informing science to cater to the receiver's needs, that is, to "provide the clientele with information in a form, format, and schedule that maximizes its effectiveness." A more significant difference is in broader conceiving of sender and receiver: these can be individual actors, groups, organizations, and even macro-social entities. Furthermore, it is posited that the two parties connect via a delivery system, which can be any communication system (as the telephone system in the Shannon and Weaver model), any information system, or even a technology-free channel (oral communication). Lastly, both the sender and the client are embedded in their respective social contexts. Due to the focus on client, its context termed "task completion environment" is particularly important.

These modifications make the model of informing system broader than the referent Shannon and Weaver model and suitable for social research ranging from a dyadic simplex (individual sender and client) to an institutional complex (e.g., an entire educational system). So for example, a simple informing system involves an accountant (the sender) who informs a manager (the client) about financial aspects of business via an accounting IS (delivery system). An example of a complex informing system refers to an entire academic discipline in which students and employers (two client groups) are informed by teachers and researchers (two sender groups) via teaching, publications and presentations (different delivery systems). Thus, informing science is an informing system. (See Gill \& Bhattacherjee, 2009.) Apparently, informing system applies to different levels of analysis - micro, mezzo, and macro.

At the outset, it is apparent that informing system and infoprocess apply to the same informing phenomena, as depicted in Figure 6. In accord with systems approach, informing system identifies parts and their relationships, while infoprocess focuses on purposive chaining of activities that can be more or less patterned.

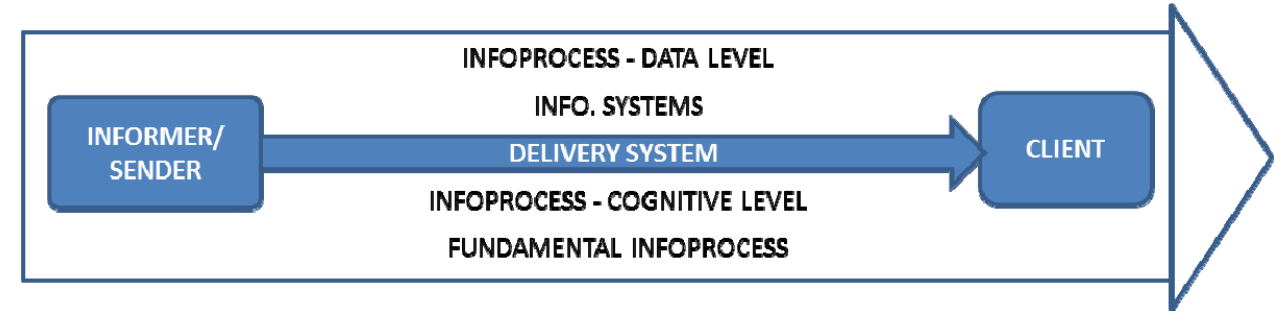

Figure 6. Relationship between Informing System and Infoprocess

I will argue, however, that the informing system model exhibits limitations that are possible to overcome with the infoprocess approach. Some of the limitations are inherited from the referent Shannon and Weaver model that is based on ideas of conduit, transport, and preservation of the transported matter (Travica, 2006). Reliability of transport via a conduit connecting sender and receiver is of primary interest. The informing system model shares this logic. It surfaces, for example, in the preserved label of sender, while the term "informer" might be more suitable. Although reliability is relevant in social interactions and communication, more than reliability is at stake. In the social world, the content communicated is essential. The difference between reliabil- 
ity and content resembles the difference between non-functional and functional requirements in the area of IS analysis and design.

The content side involves complex cognitive aspects, such as perception, knowledge, and thinking. Does the sender have perceptual, knowledge, and thinking capabilities to understand properly the client's informing needs? Can the client understand fully what is being provided by the sender? Even a more disturbing question is, Can the client comprehend accurately his or her own informing needs? The problem of missing content focus also was indicated in the examination of the academic field of management information systems (MIS) by Gill and Bhattacherjee (2009). The authors identified problems with relevance of the MIS research and teaching content that senders deliver to their respective clients. By neglecting the problem of content, informing science may encounter similar predicaments.

The bypassing of the informing content in informing science may have to do with the mainstream concept of information used in management and some other social disciplines. Bound to reification ontology and lacking analytical depth (Travica, 2011, 2012), the concept reduces information to a thing to be transported. Although this resembles the cited Shannon and Weaver (1949) model (and its proponents indeed claim allegiance to it), the similarity is misleading due to conceptual transmutations cited above. Replacing the notion of electrical signal by "information" was based on the premise that information is an entity that reduces uncertainty. However, in the referent model this reduction requires adding electrical energy that is lost (entropy) in the signal transport, while information is the measure of added energy (negative entropy). These premises imply that the transport is perfect when information is nil. Quite opposite, in the social science adaptation of the model, the perfect transport maximizes information. The best transport is when a parcel sent arrives intact. A consequence of this bypassing of client cognition problems is in asserting uncertainty reduction where this may not happen. Effects of these conceptual turns extend to date and affect those applications of the informing system model that deploy the reified concept of information. Still, as already mentioned, modeling of informing system does not preclude alternative conceptualizations of information.

The final limitation of the informing system model relevant for this discussion refers to a lack of process aspects. Related to the limitations discussed thus far, the lacking process view confines analysis to static mapping of parts and their relationships, which is germane to systems approaches. However, a process perspective is very applicable because any informing system involves interaction aspects. Interaction transpires between the informer/sender and the client, between the client and IS (delivery system), between each actor and their respective social contexts (objective environments), and possibly in other domains. The business process/infoprocess approach elaborated in preceding sections supply lenses for deepening analysis to capture these interactions and complement study of informing systems. The following discussion will demonstrate such analysis.

Analysis will combine the perspectives of infoprocess and of complex systems. Gill (2013) has argued that any task environment involves three systems, each characterized by complexity: (1) subjective mental states evoked by a task (complexity manifested as mental uncertainty or ambiguity); (2) a strategy, program or IS developed for completing a task (complexity manifested in problem space, symbolic representations); and (3) the objective, real world (complexity manifested as turbulence or ruggedness). From the IVO perspective, a business process leading to task completion represents mapping of the task (in general terms, business to do) into the problem space the client faces (see Figure 7). This business process can be partly or entirely an informing data process (consisting of data manipulation steps), and it can involve IS. The informing process and its IS support the client in coping with complexity of the real world. This is the IVO domain of cognitive processes (perception, knowledge retrieval, thinking) that complex systems theory 
signifies as mental states. The fundamental informing process facilitates resolving of this mental complexity as meaning (information) is created in the client's mind.

IVO addresses the IS life cycle and posits that IS design and data content can cause obstacles to informing. This is congruent with complex systems theory that is concerned with control of complexity arising from interaction between systems (Gill, 2013). Therefore, it follows that the client experiences extra mental complexity while using the IS. Moreover, the data content aspect of IS involves the informer/sender, thus expanding analysis to the domain of informing system. In coping with an informing task, mental complexity extends to the informer/sender attempting to understand the client's task (business to do) and informing needs (mental states or cognition). The client's task and informing needs constitute aspects of external environment for the informer/ sender. The IS both actors use is a part of the informer/ sender's problem space as well and thus a potential source of increasing complexity. In Figure 7, this idea is depicted via dashed arrows sinking into the informer/sender symbol.

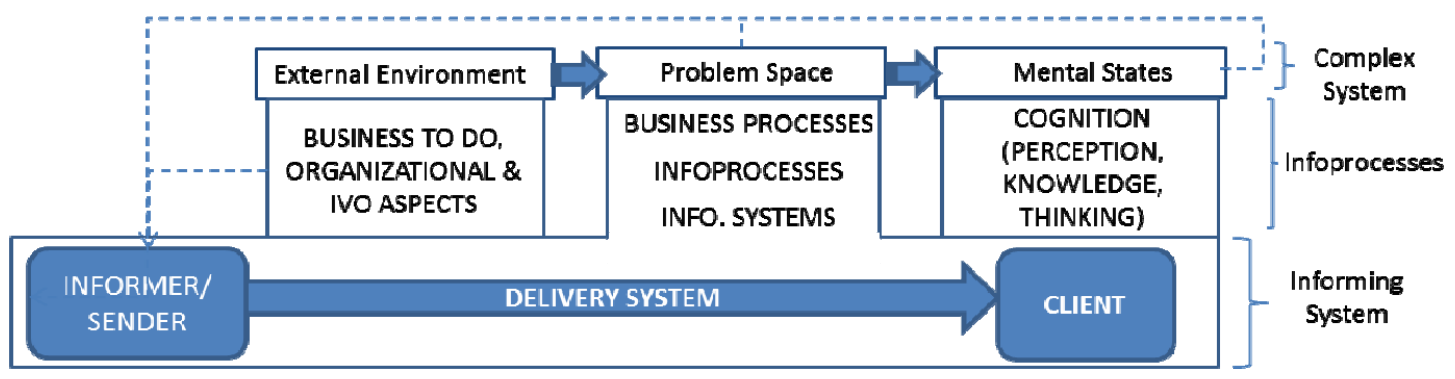

Figure 7. Relationships between Perspectives of Complex Systems, Infoprocess, and Informing System

\section{Informing System and Informing Process: Exemplary Applications}

The discussion in this section concentrates on comparative applying of the models of informing system and of infoprocess to two typical organizational operations and to one newer scenario.

Consider the task that academics are very familiar with - course syllabus updating. In the simplest version, this task can be decomposed to three sub-tasks: (1) Revise a corresponding old syllabus with new dates and locations, (2) Book exam space, and (3) Book laboratory times. Applying the model of an informing system, one can define a professor as the sender, a room scheduling clerk and a lab manager as clients, and email system the professor uses for submitting requests as delivery system. This model would account for a part of the work. To capture more of it, the model would need to be applied in reverse as well, so that the clients act as senders of responses to the professor, who becomes the client. But still one question remains: How do actors in steps 2 and 3 complete their tasks? Apparently, the application of the informing system model is complicated with the two-way communication, multiple actors, and task details pertinent to different actors.

Approaching this task from the infoprocess perspective would result in seeing the syllabus revision as an infoprocess involving three actors and their respective information systems as well as a shared email system (four in total). Points 1-3 above are steps in this infoprocess or sub-processes that have to be completed for the infoprocess to end by delivering a complete and accurate syllabus update. Specifically, the professor needs to make appropriate changes in the old syllabus with support of a word processing system. The room scheduling clerk has to record in a resource management system an appropriate room for the requested exam dates. And the lab manager has to book the lab occupation dates in a scheduling system. Communication needs to work both ways 
between the professor and the other two actors so that these understand each other, and the email system must function properly. Coordination between sub-processes can be parallel, so that professor starts the infoprocess by sending his requests, and then all three actors do their work at the same time. Timing for the syllabus update can be measured at the aggregate level as well as at the levels of sub-processes and single steps. If the end deliverable is not reached, the location of failure (human or technological) is identifiable. Overall, the infoprocess approach captures the whole picture as well as details, and yields performance indicators and determinants.

Another basis for comparing models of informing system and infoprocess will be the standard business operation of customer order fulfillment depicted in Figure A1 in the Appendix. In the simplest version, the company is a distributor and the product ordered by a corporate customer just needs to be delivered (even the details of inventory management are omitted). In a nutshell, a customer places an order, which initiates a sales clerk to create a new sales record in the sales management system; a shipping clerk is prompted to order delivery with an external party; the customer is served with a product delivered and a shipping note, which further prompts the distributor's accountant to request a payment. With the customer's payment, the process closes on the customer side. Except for the manual delivery of a product, this process is predominantly an infoprocess, featuring multiple data flows and data manipulation steps. In spite of simplifications, it still exhibits a significant complexity. Trying to capture it in the informing system model would result in hiding details (e.g., steps 3-9), obscuring the technology side behind a notion of delivery system (while multiple information systems are involved, and communication systems can be involved), and fragmenting the operation in order to fill the changing roles of sender and client (e.g., splitting off steps 7-8 and 10-13).

Both modern business and its technologies are complex. Information systems and work are enmeshed to the point that a separation is possible just for analytical purposes. Challenges of capturing such complexity with the model of an informing system have been noted (Gill \& Bhattacherjee, 2009). The level of aggregation the model presumes makes it suitable for initial positioning of a research (or practical) problem. But to sharpen research lenses one needs to deploy models that combine a holistic approach with attention to detail. The infoprocess approach lends itself as an instrument to this end.

The last example in this section refers to a new reality of virtual environments, which did not exist when Shannon and Weaver (1949) developed theory that later inspired the informing system model. How can we model research of virtual environments that only recently have surfaced? IVO differentiates between different levels of virtualness, starting with virtual identity and moving up to virtual community, organization, world... The much studied virtual world called Second Life (e.g., Saunders, Rutkowski, van Genuchten, Vogel, \& Orrego, 2011) features virtual identities of people represented by avatars, makeshift businesses that sell for "linden dollars," and major consumer brands keeping web storefronts capable of converting linden dollars to real currencies. While some avatars interact for entertainment of their owners, others take it quite seriously by engaging in class struggle against hated brands. As people extend themselves via avatars, they cognize (perceive, think, feel) and create new reality that is not just a simulation of the social and physical world. It is a unique mix of individual, social, and technological ingredients that is hard to match with other known role-playing contexts (carnivals, fairs, amusement parks, war games). The virtual world represents an epitome of a complex system (Gill, 2013), where there are no clear boundaries between mental states, problem representation, and real world.

Virtual environments trigger many questions on the research side. What model of informing is involved in a virtual world, as it seems apparent that a straightforward delivery of data is not likely to be the goal? What indeed is the delivery system when people and technology are so intimately enmeshed? Can the sender and client roles be clearly determined within dynamic interactions that involve visible and invisible members of the virtual world? These new techno-social 
realities represent significant research challenges that call for radical revamping of research instruments. Process mapping inclusive of the cognitive level of infoprocess may be a step in addressing these challenges.

\section{Infoprocesses in Mobile Enterprise}

This last section discusses how the concept of infoprocess can be used for studying mobile enterprise (ME) - a form of organizing that may spread across industries. ME is a highly spatially distributed organization whose key business processes deploy mobile information technologies and systems (cf. Stieglitz \& Brockmann, 2012). Both the process and technological criteria have to be in place for ME to exist. Some organizational forms have a long tradition of high spatial dispersion (e.g., multinational or transnational corporation, nation-wide retailers, military organizations, and churches). But the unit of analysis makes a difference in differentiating between a spatially dispersed organization and ME. For ME, the unit of analysis should be individual and group rather than organizational unit. Another important criterion is that the completion of business processes requires a significant movement of organizational members in geographical space. The mobile salesman, serviceman, and policeman or the transportation worker, family doctor, and lawyer are familiar examples approximating these characteristics.

A significant change recent decades have brought to bear is that the work of mobile workers became more data, knowledge, and communication intensive. While visiting a sales prospect, the salesman needs access to product and customer records. The serviceman working on the customer premises may need to get help in troubleshooting malfunctioning machinery and to check the inventory of spare parts. While cruising around a district, the policeman needs to check vehicle registration records in order to enforce law. In the competitive transportation industry, truck drivers live on wheels while being in continuous communication with dispatchers who strive to optimize truck loads, distances, and timing, not to mention the incessant urge motivating both parties to communicate over road conditions. To raise the quality and efficiency of service, both the mobile health worker and lawyer need to access various databases and knowledge work systems. And the list of examples continues, as the mobile work mode keeps extending into other sectors.

A technological transformation of the mobile worker started with microcomputers in the $1980 \mathrm{~s}$. But before the Internet era dawned, the mobile worker could rely just on the landline telephone, pager, and radio communication systems, while having to carry mobile information systems literally in the briefcase (a laptop and CD-ROM-mounted databases). Then, the technological development accelerated and expanded in coverage. It now includes the infrastructure (telecommunication networks), all the layers in the client-server architecture, a plethora of micro computing devices on the client side (smart phones, various tablet devices), and system development technologies (e.g., component-based application software, and Service Oriented Architecture). In addition, Cloud Computing has emerged as a new business model for delivery of system services that take advantage of the distributed, pervasive, and Internet-centric trends.

All these changes chart the territory for a rise of ME. Sensitive detection methods are necessary for identifying transformation toward the mobile mode. Consider this example from health care. A hospital that uses cell phones for informing the staff about changes in patient state satisfies the technological criterion. Still, it may not be an ME. A community health care service that deploys mobile physicians and nurses and coordinates them via mobile systems is more likely to qualify as a ME. As already stated, necessary conditions for ME to exist are both the process and technological dimensions. From the IVO perspective, infoprocesses embedded in health delivery process should be particularly scrutinized. In addition, since the motive for morphing into ME is in increasing efficiency and effectiveness (Stieglitz \& Brockmann, 2012), a differential in organizational performance has to be included in modeling of ME. 
A model of ME that accounts for the discussed criteria is shown in Figure 8. Metaphor fans may as well picture $\mathrm{ME}$ as a rocket for traversing cosmic spaces. Mobile information technologies, information systems, and telecommunications networks are building blocks of distributed infoprocesses. For example, a mobile information technology is a tablet device, and a mobile information system is the one that deploys mobile information technologies, data flows distributed in space and carried by networks, possibly some location-bound parts (e.g., databases at company premises), and distributed data storage and/or processing services. Infoprocess design depends both on business needs and technological capabilities and limitations. For example, data entry and reading can rest on simpler technologies, such as tablet devices or the smart phone. In contrast, data processing steps would require a tablet PC. For infoprocess steps to be connected in a flow, support of telecommunications networks is necessary. Third party services, such as Cloud Computing may also be engaged via networks.

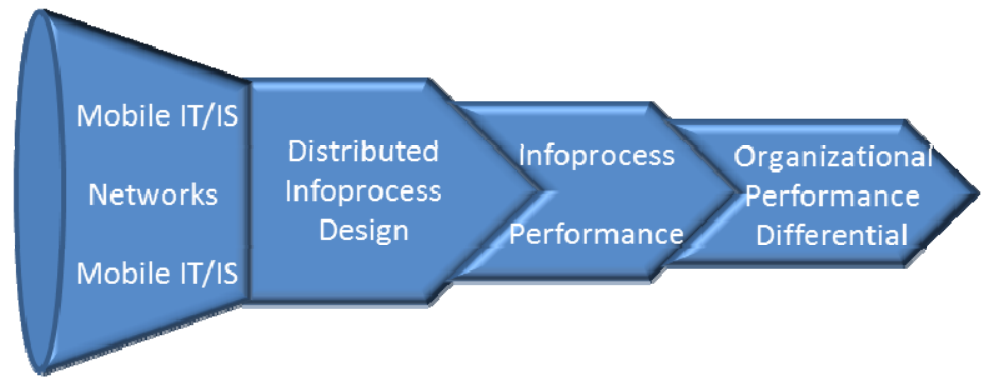

Figure 8. Mobile Enterprise

All these considerations refer to infoprocess composition as one of design aspects. Coordination is also a critical design aspect in ME. Bridging the geographic space in random patterns creates a challenge for streamlining infoprocess steps into smooth flows. For example, sequential interdependence between spatially distributed steps (steps chained in a linear sequence) bears a risk of delays caused by telecommunication factors and/or process performers (informers and clients alike) working in isolation. Historically, similar problems have been noted in the practice of telecommuting. Furthermore, an ME infoprocess may need to be flexible in terms of different modes of accessing distributed system services.

As indicated in the model of ME (Figure 8), infoprocess design determines the performance of infoprocesses. The process performance metrics discussed earlier serve infoprocesses as well. By becoming a ME an organization should be able to improve its infoprocesses and the corresponding business processes with regard to timing, monetary cost, and client (customer) value. Organizational performance should improve as the end-result with regard to financial results, quality, service, or some other indicators pertaining to an industry or a market. The criterion of performance differential helps to determine if an organization with distributed individual/group work really functions as an ME. Some examples of the differential are fuller and otherwise impossible services delivered at customer premises, continuous project work in teams with highly dispersed membership, global sourcing, mobile knowledge work enabled by continuous access to knowledge bases (Gafni \& Geri, 2013), and global extensions of marketing and sales involving a mobile customer.

IVO can be deployed in a normative fashion for defining requirements for organizational design of ME. Infoprocesses are in the focus. The model depicted in Figure 8 can guide this exercise. Distributed ME processes set important requirements for homo informaticus. An ME needs people who are used to working outside a familiar office environment. They are able to adjust to various and even unusual conditions (e.g., noise and crowd as well as the total opposite - isolation). ME members are independent professionals that exhibit high self-efficacy. This includes cognitive maturity that allows an ME member to solve professional problems on their own. They 
boldly adopt digital technologies, believing that technology and business feed each other. They face technological challenges that may abound in the cross-platform, network-dependent environment. To use a military metaphor, an ME professional resembles a commando soldier as opposed to massive military formations that resemble office employees.

From the perspective of complex systems theory, ME professionals need to be creative in defining the problems space to accommodate a rugged real world (Gill, 2013). The effectiveness of their strategies (infoprocesses, work methods, experience), may vary significantly with differing contexts that mobile business may bring them to even on a daily basis. The professionals also need to be capable of controlling mental complexity precipitated by both a rugged real world and efforts put in its representation through IS and otherwise.

Managers in ME also face challenging requirements. They may reside in stationary control centers or also be mobile. Managers also face rugged real worlds and problem spaces, as they have to adjust to working with invisible employees, without having convenience of continuous control (even if electronically). Nevertheless, they need to provide support, exercise necessary control, and be able to see it to the end of work processes.

When the work so requires, ME members take on the team player role. This capability pertains to the aspect of groupomatics. Its staple characteristic is spatially distributed group context. Groupbased cognitive processes of collective memory and collective mind constitute requirements for various designs of infoprocess at the data level and the corresponding technological support. The infostructure aspect of $\mathrm{ME}$ requires deciding between centralized and distributed databases, flexible solutions regarding access privileges in the case of project-driven organizations, and optimizing formalization of data standards for a type of organization at hand (e.g., excessive liberty in recording problem solving experiences could impair knowledge sharing, while excessive standardization could constrict the input).

Infoculture is investigated by observing organizational culture and asking questions about information technologies/systems, data and knowledge (Travica, 2012). Applied to ME, one can ask about the perceived relationship between organization members and information technologies, the purpose of information systems in the ME, desired dynamics of systems' change, and desired/actual methods of handling data and managing knowledge. The answers are likely to vary depending on the industry and a specific organization. In an "ideal ME," the members could see themselves as competent users and self-starters; technology should be in service of the performance of distributed business and would be desired to change with both business and technological demands.

The stance of infopolitics illuminates power that springs from controlling data/IT, possessing knowledge, and managing meaning. In general, the profile of homo informaticus that fits ME and dispersed processes requires a broader distribution of infopower rather than its concentration in the management function. On the other hand, a lack of immediate supervision and implied checks-and-balances could give rise to islands of accumulated power based on withholding or monopolizing new data. This imbalance can be critical in certain industries, such government, health care, and finance. It can get aggravated if monopoly over new and important data is combined with exclusive expertise and opportunities of manipulative management of impressions on the client side (Bradshaw-Camball \& Murray, 1991). In addition, the security dimension influences infopolitics in ME. Since the data are physically distributed across the company premises, individual members, and Cloud locations, theft and unauthorized access are continuous risks. If a beneficiary is able to turn such data leaks in influence over competitors, the damaged ME suffers a power loss. The multiplicity of IVO aspects and their interaction indicate a significant ruggedness (Gill, 2013) of the real world engulfing ME. 


\section{Conclusion}

The preceding discussion was conceptual in character, supplied with expanded examples from more and less typical organizational scenarios. This conceptual character was in accord with the eminently theoretical goal of this article to explore the relationship between concepts of informing process and of informing systems. This limitation needs to be overcome in future research by testing that relationship in empirical investigation.

I have argued that the conceptualization of infoprocess developed within IVO (Informing View of Organization) is supplementary to the model of informing system developed within informing science. Both are preoccupied with problems of informing between actors involved in the social context. Both share the focus on the client side in informing, and both capture a big picture of informing. On the differences side, the optic of informing systems is useful for initial positioning of an informing phenomenon, while the infoprocess lens illuminates interaction aspects of it. It does it so in process terms by identifying multiple senders and clients that often exchange roles, and by capturing technological complexity behind the delivery system within an informing system. The analytical capacity of infoprocess also lies in its composition involving three-layers as well as in its relationships with other IVO aspects. Informing science research can benefit from deploying the infoprocess approach, and particularly so by concentrating on informing in new techno-social and organizational contexts.

In the discussion, I have also demonstrated parallels between informing systems, infoprocess, and complex systems. The latter two approaches share the informing science's goal of improving informing, even though they express it differently. Complex systems theory concentrates on complexity control. It posits that the client's informing deteriorates if complexity uncontrollably increases via amplifying loops between the real world, problem space, and mental states (Gill, 2013). The infoprocess approach as part of IVO focuses on aligning informing agents and organization in order to advance organizational intelligence. This intelligence manifests itself remarkably in economic sustainability and in a capability of creating an engaging and dignified workplace for organization members (Travica, in press). Future research may test a plausible proposition that complexity control is an indication of organizational intelligence. Entering the stance of informing systems and the assumption that complexity exists also on the informer/sender side gives rise to several questions: How do complex systems on the client and on the informer/sender side interact? How do these interactions affect overall complexity? Does complexity control in such an expanded informing system correlate with organizational intelligence? These questions may generate interesting research of both a theoretical and practical importance.

\section{References}

Bednar, P., \& Welch, C. (2009). Inquiry into informing systems. In T. G. Gill \& E. Cohen (Eds.), Foundations of informing science: 1999-2008 (pp. 459-501). Santa Rosa, CA: Informing Science Press.

Barnard, C. (1938). The functions of the executive. Cambridge, MA: Harvard University Press.

Boland, R. (1987). The in-formation of information systems. In R. Boland \& A. Hirschheim (Eds.), Critical issues in information systems research. New York, NY: Wiley.

Bradshaw-Camball, P., \& Murray, V. (1991). Illusions and other games. A trifocal view of organizational politics. Organization Science, 2(4), 379-398.

Cohen, E. (1999/2009). Reconceptualizing information systems as a field of the discipline informing science: From ugly duckling to swan. In Gill, T. G, and Cohen, E. (Eds.), Foundations of informing science: 1999-2008 (pp. 7-19). Santa Rosa, CA: Informing Science Press. (Reprinted from the Journal of Computing and Information Technology, 7(3), 213-219, 1999.) 
Cronen, V., \& Pearce, W. B. (1982). The coordinated management of meaning: A theory of communication. In F. E. X. Dance (Ed.), Human communication theory (pp. 61-89). New York: Harper \& Row.

Davenport, T. (1993). Process innovation: Reengineering work through information technology. Boston, MA: Harvard Business School Press.

Davenport, T. (2010). Process management for knowledge work. In J. vom Brocke \& M. Rosemann (Eds.), Handbook on business process management: Introduction, methods and information systems, Vol. 1 (pp. 17-36). Berlin: Springer.

Gafni, R., \& Geri, N. (2013). Adoption patterns of a mobile juridical knowledge base. Journal of Information, Information Technology, and Organizations, 8, 25-39. Retrieved from http://www.iiakm.org/jiito/articles/Volume_8/JIITOv8p025-039Gafni-Geri.pdf

Gill, T. G. (2013). Complexity, cybernetics, and informing science: Building a better mousetrap. Systemics, Cybernetics, and Informatics, 11(9), 53-68.

Gill, T. G., \& Bhattacherjee, A. (2009). Informing science at a crossroads: The role of the client. In T. G. Gill \& E. Cohen (Eds.), Foundations of informing science: 1999-2008 (pp. 21-55). Santa Rosa, CA: Informing Science Press.

Gill, T. G., \& Cohen, E. (2009) (Eds.). Foundations of informing science: 1999-2008. Santa Rosa, CA: Informing Science Press.

Hammer, M. (1996). Beyond reengineering: How the process-centered organization is changing our work and our lives. New York, NY: HarperBusiness.

Hammer, M. (2010). What is business process management? In J. vom Brocke \& M. Rosemann (Eds.), Handbook on business process management: Introduction, methods and information systems, Vol. 1 (pp. 3-16). Berlin: Springer.

Hammer, M., \& Champy, J. (Eds.). (1993). Reengineering the corporation: A manifesto for business revolution. New York: HarperBusiness.

Harmon, P. (2007). Business process change. San Francisco, CA: Morgan Kaufmann.

Hatch, M. J. (1997). Organization theory: Modern, symbolic, and postmodern perspectives. Oxford, UK: Oxford University Press.

Knox, K. T. (2009). Information and informing science. In T. G. Gill \& E. Cohen (Eds.), Foundations of informing science: 1999-2008 (pp. 135-158). Santa Rosa, CA: Informing Science Press.

Saunders, C., Rutkowski, A. F., van Genuchten, M., Vogel, D., \& Orrego, J. (2011). Virtual theory space and place: Theory and test. MIS Quarterly, 35(4), 1079-1098.

Scott, W. (1992). Organizations: Rational, natural and open systems. Englewood Cliffs, NJ: Prentice Hall.

Shannon, C., \& Weaver, W. (1949). The mathematical theory of communication. Urbana, IL: University of Illinois Press.

Stieglitz, S., \& Brockmann, T. (2012). Increasing organizational performance by transforming into a mobile enterprise. MIS Quarterly Executive.

Travica, B. (2005a). Information view of organization. Journal of International Technology and Information Management, 14(3), 1-20. Key-note paper.

Travica, B. (2005b). Information politics and information culture: Case study. Informing Science: The International Journal of an Emerging Transdiscipline, 8, 211-245. Retrieved from http://www.inform.nu/Articles/Vol8/v8p211-244Travica.pdf

Travica, B. (2006). Information systems field at the forks: Cherish diversity of perish. Issues in Informing Science and Information Technology, 3, 647 - 665. 
Travica, B. (2007). Of Monsters, Divinations, Costly Dumbness and Fumbling: Adopting a Self-Service System. Journal of Information, Information Technology, and Organizations, 2, 15-29. Retrieved from http://www.informingscience.org/jiito/articles/JIITOv2p015-029Travica258.pdf

Travica, B. (2011). Back to basics of informing: The INIS Principle. Interdisciplinary Journal of Information, Knowledge, and Management, 6, 177-196. Retrieved from http://www.ijikm.org/Volume6/IJIKMv6p177-196Travica549.pdf

Travica, B. (2012). Culture of informing: A case of consulting company. Economic and Business Review, 14(3), 223-249.

Travica, B. (in press). Examining the informing view of organization: Applying theoretical and managerial approaches. Hershey, PA: IGI Global.

vom Brocke, J., \& Rosemann, M. (Eds.). (2010). Handbook on business process management: Introduction, methods and information systems, Vol. 1, 2. Berlin: Springer.

Wong, W. P. (2013). Business-process management: A proposed framework for future research. Total Quality Management \& Business Excellence, 24(5-6), 719-732.

\section{Appendix}

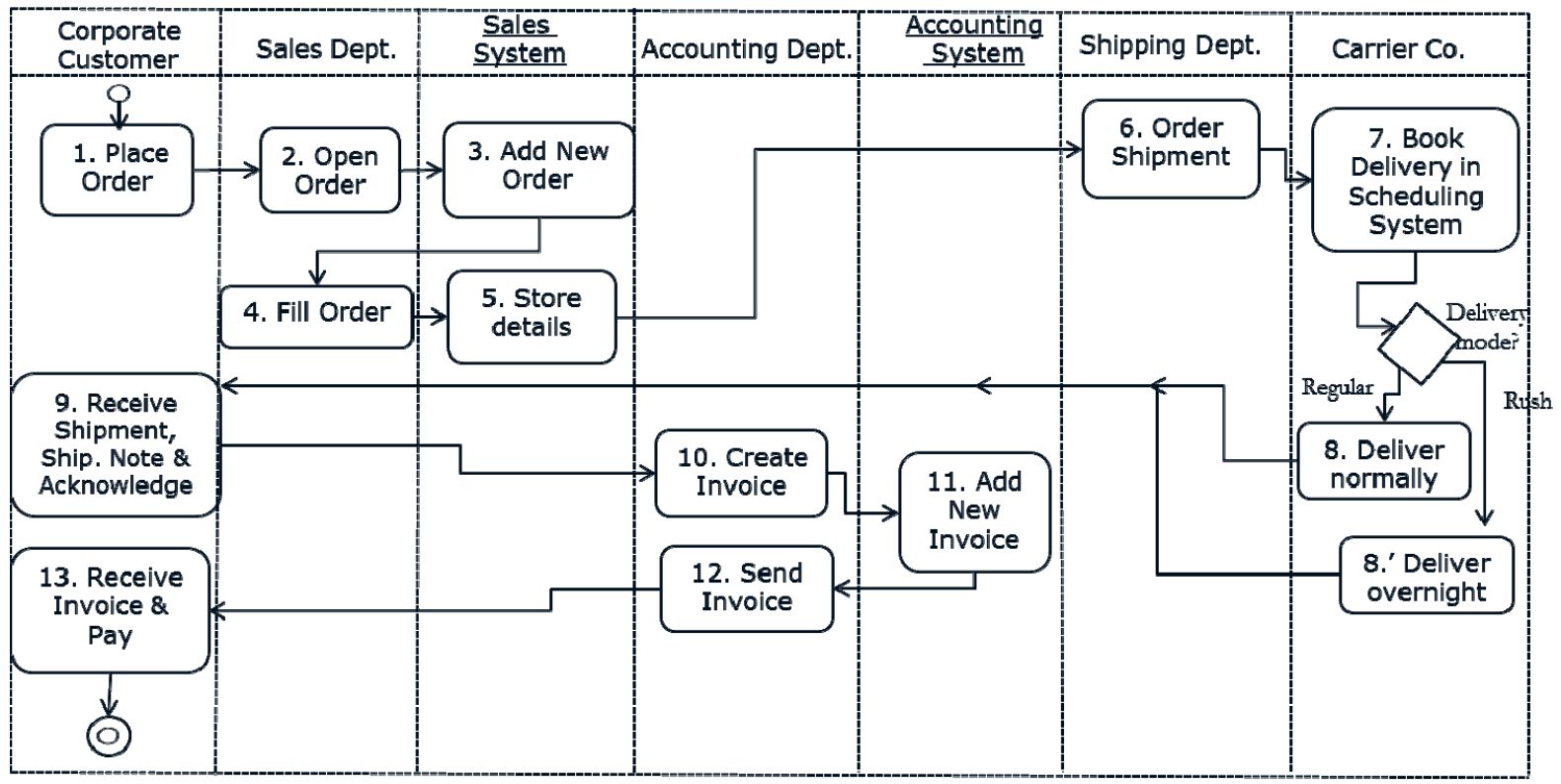

Figure A1. Customer Order Fulfillment Process (simplified)

\section{Biography}

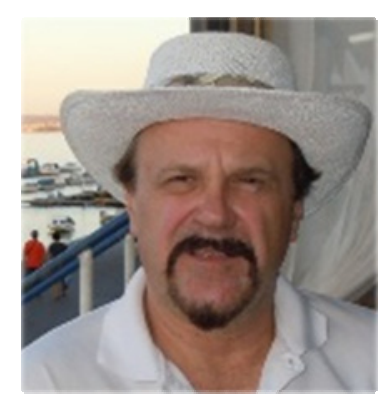

Bob Travica teaches information systems in the I.H. Asper School of Business at The University of Manitoba in Canada. He completed Doctoral and Master's studies in the United States. Bob has worked as academic in the North America, Latin America, and Europe. He also worked in the software industry, corporate communications, and journalism in Europe. In his research, Bob focuses on the informing view of organization, organizational evolution with information and communication technologies, and information systems in the international context. 